\title{
De las psicopatologías críticas a la crítica de la psicopatología
}

RESUMEN: Se critican las tres propuestas de psicopatología enfrentadas en una mesa de una actividad científica de la AEN por considerar que, a pesar de sus diferencias, tienen en común la pretensión de buscar en la psicopatología una base científica para la práctica de la Psiquiatría y la Psicología Clínica y de hacerlo a través de una substancialización del síntoma. Se contrapone a ellas una crítica de la psicopatología en la que los síntomas aparecen como marcadores de constructos que tienen como objeto guiar la actividad de los profesionales de la salud mental y que no pueden ser entendidos sin tomar ésta en consideración

PALABRAS CLAVE: Psicopatología, crítica de la psicopatología

El 7 de junio del 2001, la Asociación Madrileña de Salud Mental tuvo el acierto de organizar, en sus XVII jornadas, una mesa sobre la vigencia de la psicopatología que coordinó Manuel Chávez. En ellas Rogelio Luque defendió la propuesta de psicopatología descriptiva en la que hoy colaboran con el grupo de Berrios, en Cambridge, una parte de los discípulos de Carlos Castilla del Pino,

\begin{abstract}
We discuss three models of critical Psychopathology that were proposed in a symposium of the AEN. We consider that, although they are different, they have in common the attempt of looking for a scientific basis for Psychiatry and Clinical Psychology that looks for a substance in symptoms. We propose a critic of psychopathology that implies looking symptoms as cues of constructs aiming to serve as a guide for mental health professional activities, and that can not be understood whiteout considering this activity

KEY WORDS: Psychopathology, Critics of Psychopathology
\end{abstract}

como él mismo o José Villagran. Amparo Belloch disertó sobre la psicopatología cognitiva. Fernando Colina reivindicó una psicopatología hermenéutica en una ponencia muy crítica con las otras dos posturas. El debate posterior les permitió confrontar y matizar las respectivas posiciones. Fue un debate vivo. Porque son tres posturas críticas y eran tres polemistas brillantes. 
Se me antoja, sin embargo, que pese a las diferencias allí debatidas (que no se me escapan) las tres posturas comparten una idea básica que, a mi, me cuesta aceptar. Entiendo que las tres mantienen la ilusión de una psicopatología que como la psico(pato)logía que soñó, y con la que nos hizo soñar a tantos, Carlos Castilla del Pino, funciona como la ciencia básica capaz de proporcionar fundamento a prácticas como la de la Psiquiatría o la Psicología Clínica.

Se trata de una idea que ha guiado bellos textos y ha inspirado reflexiones interesantes y útiles, como se encargaron de recordarnos los ponentes de la mesa que comentamos. Pero me parece que es una idea que alimenta espejismos (como el de la existencia de una historia de la psicopatología, explicable por sus leyes internas), porque ella misma es una ilusión, una construcción ideológica (entendiendo ideología como falsa conciencia) que se sostiene porque cumple su función de calmar las angustias de los profesionales del ramo.

Pueden forzarse los hechos para hacer aparecer la historia de la psiquiatría y la atención a la salud mental como un intento de puesta en juego de ideas que pudieran entenderse como parte de ese cuerpo científico que pudiéramos llamar psicopatología. En esta línea puede reclamarse la necesidad de recuperar algunas ideas, o lamentarse el torpe abandono de planteamientos que fueron o parecieron fructíferos. Así pueden detectarse líneas de progreso o lamentarse estancamientos o retrocesos. Y algo de todo eso se hizo en las jornadas en la Asociación Madrileña.
Pero me parece que lo sucedido y lo por suceder al respecto se entiende mejor si consideramos que la psicopatología, más que ser la ciencia fundamental de la Psiquiatría y la Psicología Clínica, es la ideología (de nuevo en el sentido de falsa conciencia) con la que los Psiquiatras y Psicólogos Clínicos justifican a posteriori una práctica cuyos fundamentos y determinantes están en otro lugar.

No es que el asilo se fundamente en la psicopatología descriptiva, que floreció en Francia en el siglo XIX. Es que la psicopatología descriptiva es la visión de la locura que es conformada por la actividad de acompañar y cuidar a los locos en los asilos. No es que el psicoanálisis sea fundamentalmente en la propuesta psicopatológica de Freud (por otra parte ¿en cuál de ellas?) sino que esas propuestas resultan del intento de explicar lo que Freud se iba viendo obligado a hacer cuando intentaba actuar mediante la palabra sobre los síntomas de los pacientes que acudían a su consulta. No es que la idea de enfermedad organizada en la cabeza de Kraepelin permita la articulación de una nueva actitud en la medicina de la mente. Es que la exigencia social de esa nueva actitud impone la nueva visión. Y no es que hoy nuestra mala cabeza y falta de espíritu reflexivo nos haya llevado a un empobrecimiento brutal de la psicopatología que puede ilustrarse con los textos del DSM y las guías clínicas, sino que, quizás a nuestro pesar, hemos configurado ante nuestros ojos la psicopatología que sirve para guiar y dar cuenta de nuestro trabajo como prescriptores de los remedios cuya venta 
mueve, hoy por hoy, el negocio de la salud. Lo que las propuestas psicopatológicas que critican con éxito el empobrecimiento de la psicopatología contraponen a él son ideologías de los psiquiatras y psicólogos clínicos que no se resignan a ser prescriptores, y pretenden participar en la investigación sobre los remedios (los del grupo de Cambridge, Fernando Colina y los neuropsicólogos cognitivos, por citar algunos con representación en la mesa de Madrid, son buenos ejemplos).

Una crítica de la psicopatología nos obligara a un cambio de objeto de interés. Mientras las psicopatologías se han ocupado de atrapar lo sustancial del síntoma, lo que la critica de la psicopatología pondrá de manifiesto es que en el síntoma no hay nada de sustancial (como resultó que no habría nada de sustancial en el dinero a la luz de la crítica de la economía política). Lo que la crítica de la psicopatología habrá de mostrar es el proceso por el que se produce la aparente sustanciación del síntoma al servicio de una organización social de las relaciones de ayuda.

No hay en la naturaleza síntomas o enfermedades esperando a ser descubiertas por psicopatólogos (como no las hay esperando la mirada de anatomapatólogos, microbiólogos u otras). Los síntomas, y las enfermedades, son constructos que ponen en juego al menos 3 elementos:

1.- Una cultura que define un sufrimiento como morboso.

2.- Unos agentes (médicos, chamanes o sacerdotes) a los que esta sociedad reconoce como capacitados para actuar sobre ellos.
3.- Unos pacientes que acuden o son llevados a ellos porque ellos o sus allegados consideran que padecen ese tipo de sufrimiento.

La función de estos constructos es servir a estos agentes para hacer predicciones sobre los resultados de sus intervenciones. La distinción entre distintas enfermedades adquiere sentido en la medida que sirve para poner en marcha distintos procedimientos y para hacer predicciones sobre cuáles serán los resultados obtenidos con estos. Los mayas y sus sanadores saben qué hacer y qué cabe esperar que suceda con los espantos y qué hacer con los males echados o el k'ak'al ontonil. o ek ti'ol. Nuestras familias y médicos saben qué hacer y qué cabe esperar que suceda con la varicela y qué hacer con el síndrome de Down, la tuberculosis o los ataques de pánico. Por eso, aunque tengan el mismo agente causal, la varicela y el herpes zoster son enfermedades diferentes.

Si esto es así, el síntoma, la enfermedad es también función del proceso de intervención. Las psicopatologías tal y como las conocemos, ocultan este hecho importante como ocultan que es un contexto cultural el que le otorga a los fenómenos el carácter de morbosos.

Los nuevos instrumentos de intervención (las nuevas formas de ayuda) hacen surgir nuevas "entidades" morbosas (la depresión "atípica" es la que no responde a antidepresivos). Como las hacen surgir los nuevos consensos sociales (la obesidad mórbida o la adición a 
Internet). Algunas han querido ver en esto una muestra de la debilidad de la ciencia psicopatológica (o de la patología en general). Probablemente es mas sensato que consideremos que esto no muestra una debilidad, sino la naturaleza misma de la disciplina. Porque aunque eso nos prive de una romántica ilusión, nos permitirán, al menos, saber sobre qué y con qué instrumentos hemos de actuar si queremos influir en ese proceso de definición de los objetos morbosos, o sea de las condiciones que convierten a algunos sujetos en merecedores legitimados de nuestra actividad de ayuda.

\section{BIBLIOGRAFÍA:}

Belloch A., Sandín B., Ramos F. Psicología patológica (2 volúmenes). Madrid: McGraw Hill, 1994

Colina F. El saber delirante. Madrid: Síntesis, 2001

Fernández Liria A. Una confluencia en las narrativas. En Fernández Liria A., Rodríguez Vega B. La práctica de la psicoterapia; construcción de narrativas terapéuticas. Bilbao: Desclée de Brouwer, 2001.

Luque R., Villagrán Jm. Psicopatología descriptiva. Nuevas tendencias. Madrid: Trotta 2000

* Coordinador de Salud Mental. Área de Madrid. Prof. Asociado de Psiquiatría. Universidad de Alcalá de Henares

Fecha de recepción: agosto 2001 